\title{
Cavitands with Introverted Functionality Stabilize Reactive Intermediates
}

Richard J. Hooley, Per Restorp, Tetsuo Iwasawa and Julius Rebek, Jr.

The Skaggs Institute for Chemical Biology and the Department of Chemistry, The Scripps Research Institute, 10550 N. Torrey Pines Rd., La Jolla, CA 92037

jrebek@scripps.edu

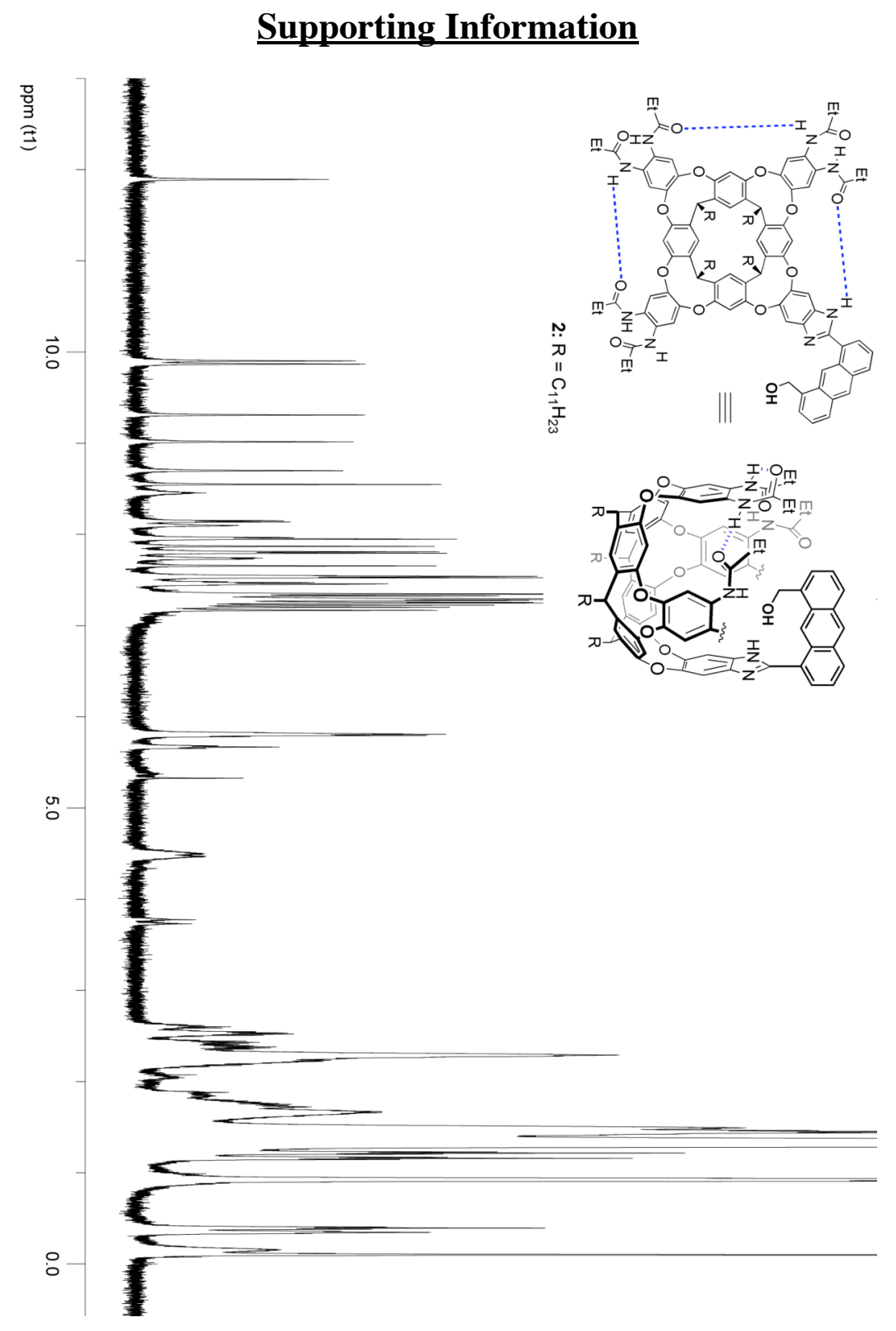

Figure S1. ${ }^{1} \mathrm{H} \mathrm{NMR}$ spectrum of cavitand 2, $600 \mathrm{MHz}, \mathrm{CDCl}_{3}, 300 \mathrm{~K}$ 

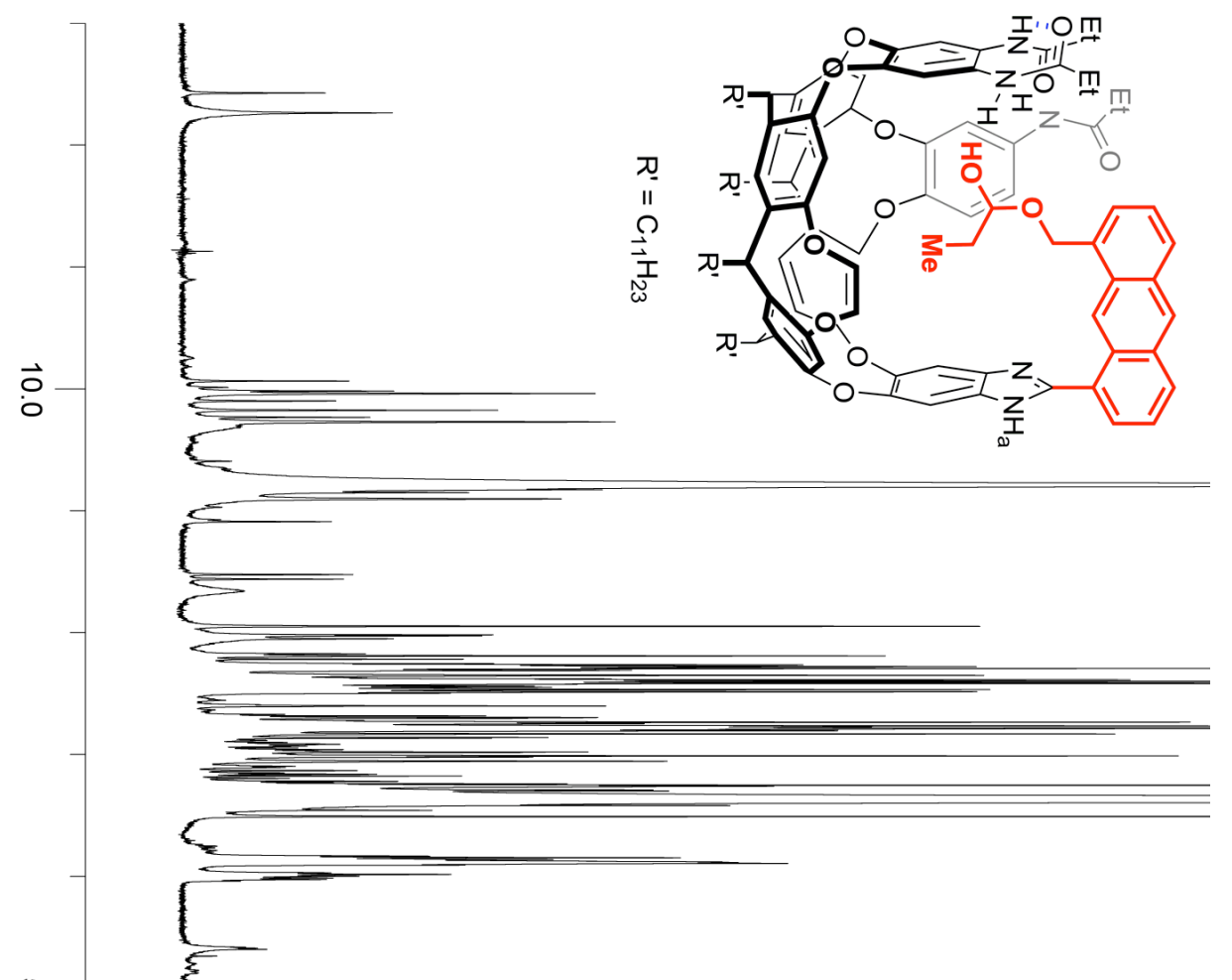

(1)
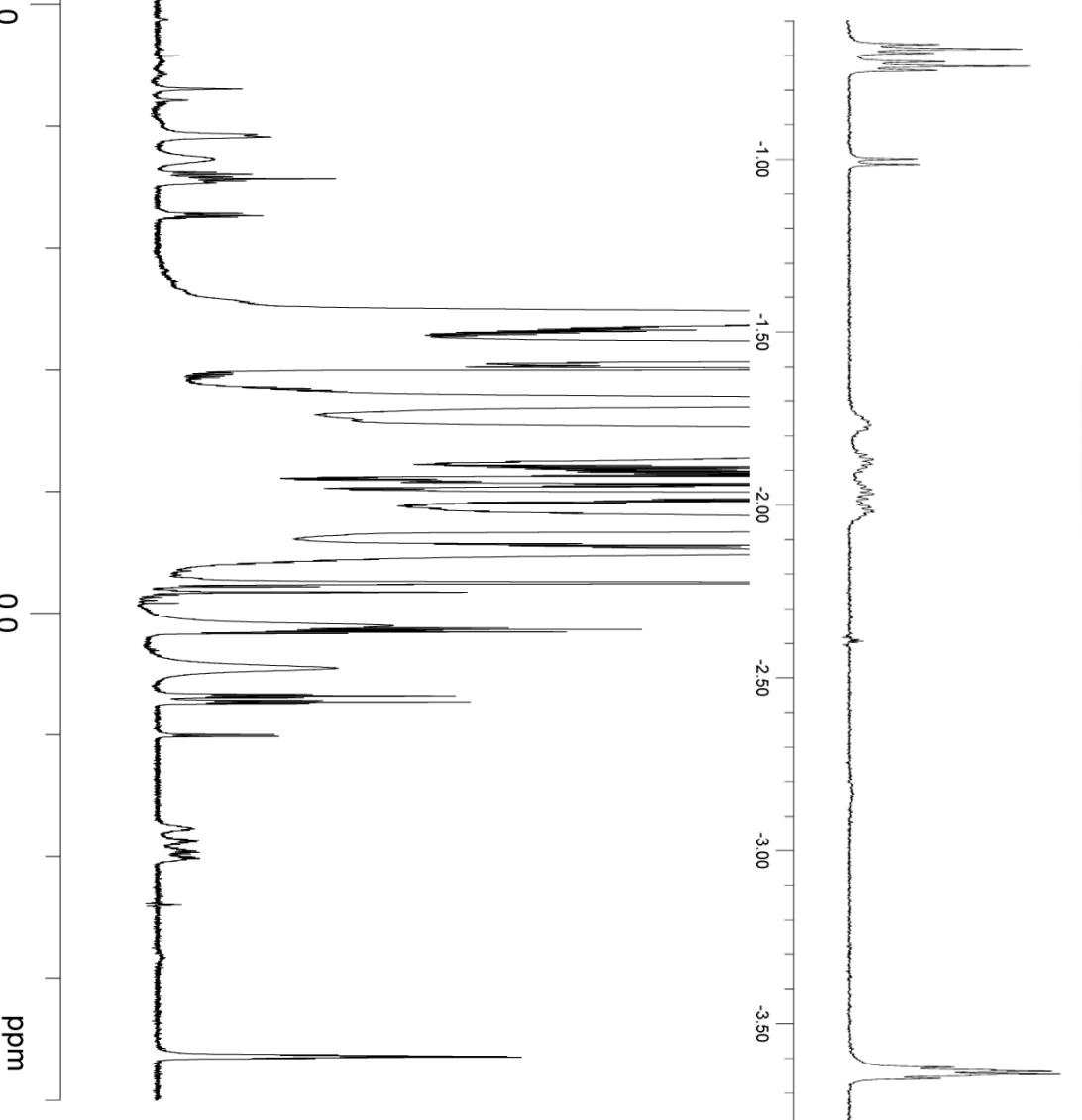

Figure $\boldsymbol{S} 2 .{ }^{1} \mathrm{H}$ NMR spectrum of the complex $\mathbf{2 \cdot 3}$ formed by exposure of cavitand $\mathbf{2}$ to propionaldehyde 3, $600 \mathrm{MHz}$, mesitylene- $d_{12}, 300 \mathrm{~K}$. 


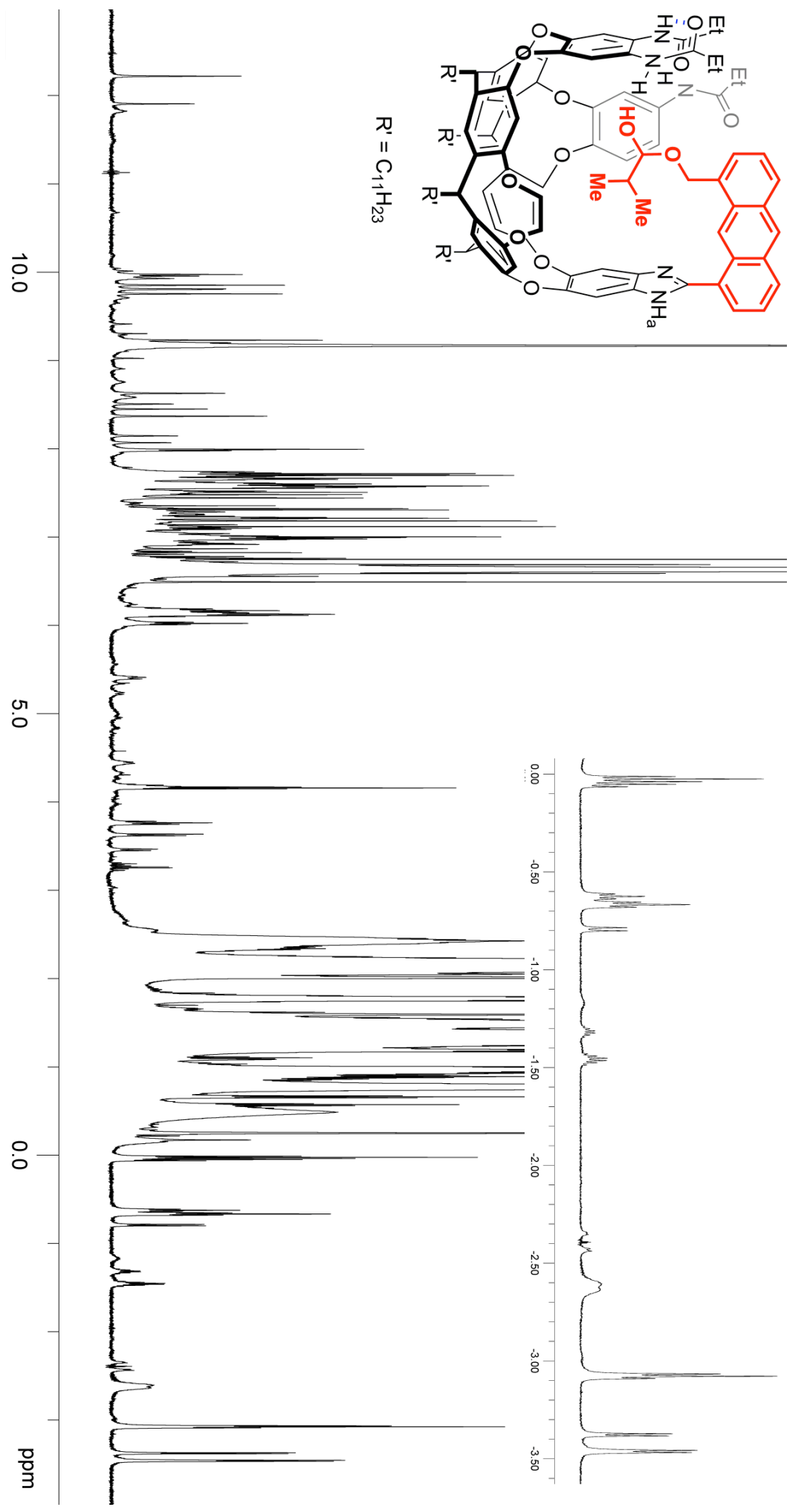

Figure S3. ${ }^{1} \mathrm{H}$ NMR spectrum of the complex $\mathbf{2 \bullet 4}$ formed by exposure of cavitand $\mathbf{2}$ to isobutyraldehyde 4, $600 \mathrm{MHz}$, mesitylene- $d_{12}, 300 \mathrm{~K}$. 


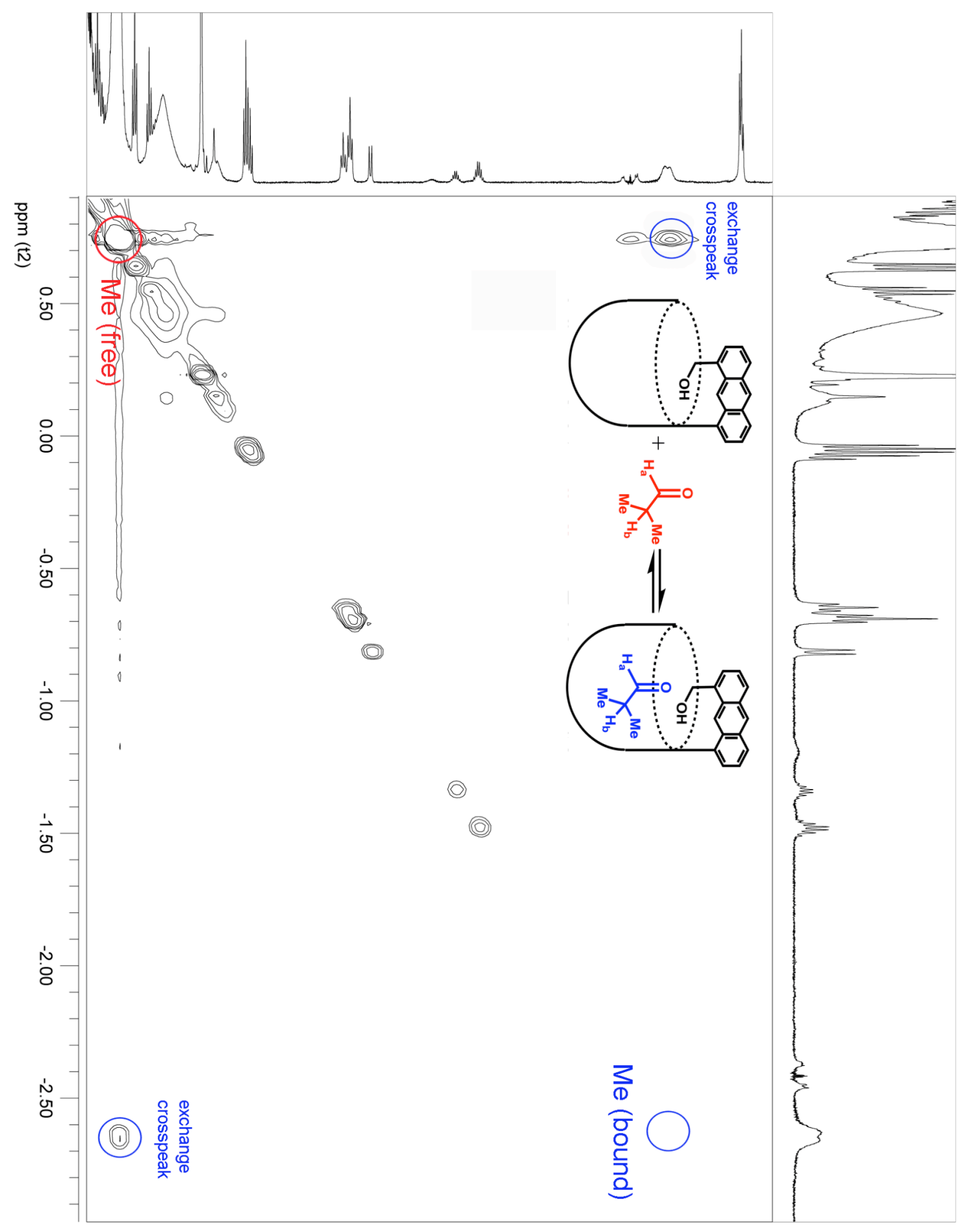

Figure S4. Expansion of the 2D NOESY spectrum of the complex $\mathbf{2 \cdot 4}$ formed by exposure of cavitand 2 to isobutyraldehyde 4, $600 \mathrm{MHz}$, mesitylene- $d_{12}, 300 \mathrm{~K}, 300 \mathrm{~ms}$ mixing time. The blue circles show chemical exchange crosspeaks between noncovalently bound and free aldehyde $\mathbf{4}$, but not between free 4 and bound hemiacetal. The diagonal peak for bound $4(\delta=-2.6 \mathrm{ppm})$ is faint due to the rapid exchange and large excess of free aldehyde. 


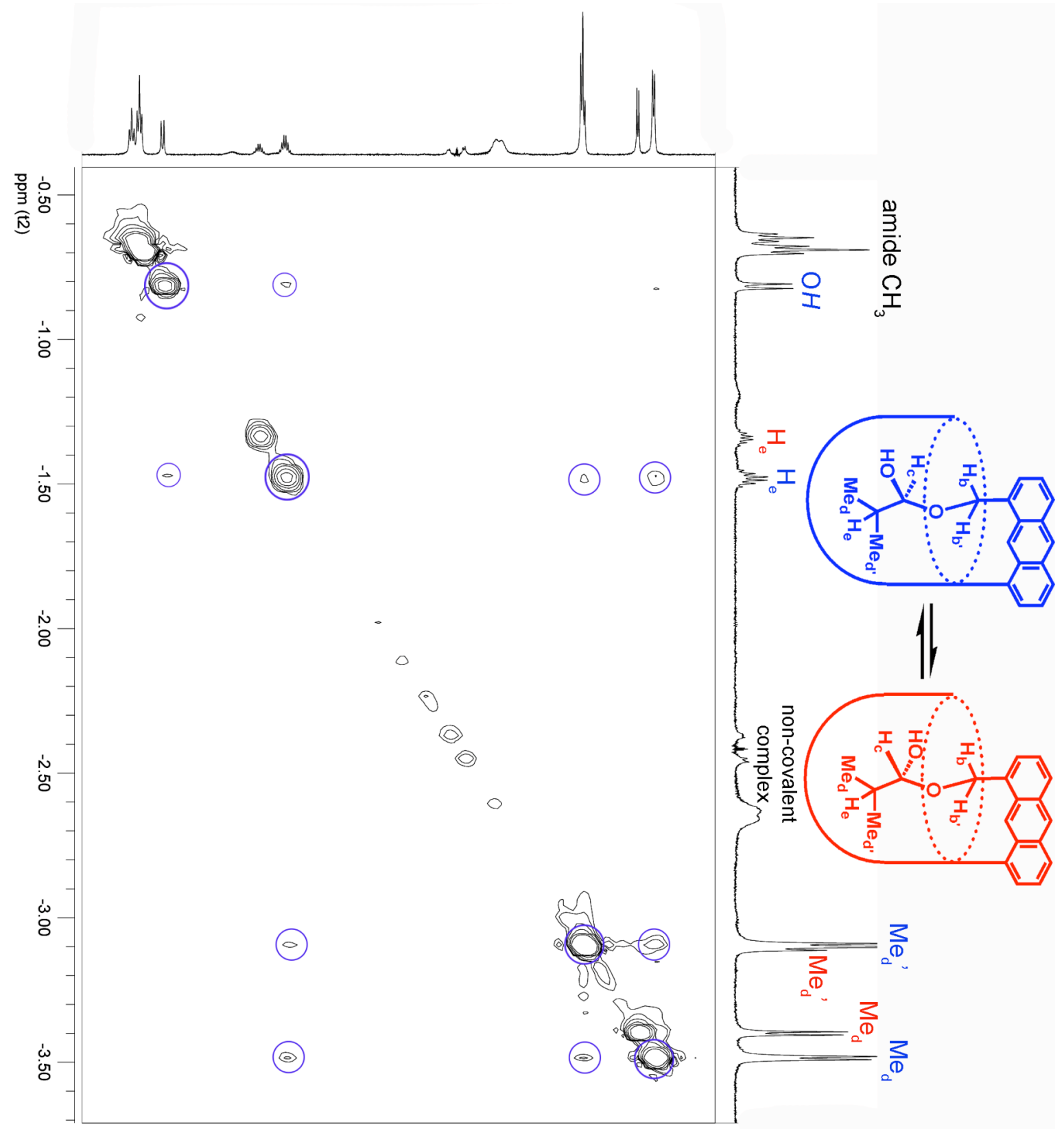

Figure S5. Expansion of the 2D NOESY spectrum of the complex $\mathbf{2 \bullet 4}$ formed by exposure of cavitand 2 to isobutyraldehyde 4, $600 \mathrm{MHz}$, mesitylene- $d_{12}, 300 \mathrm{~K}, 300 \mathrm{~ms}$ mixing time. The blue circles show NOE crosspeaks between protons belonging to one diastereomer of hemiacetal (blue color). The NOE correlation between $\mathrm{H}_{e}$ and the doublet, $\delta=-0.8 \mathrm{ppm}$ identifies that doublet as belonging to the hemiacetal $\mathrm{OH}$ for that diastereomer. The crosspeaks for the minor diastereomer are too faint to observe in 36 scans. 


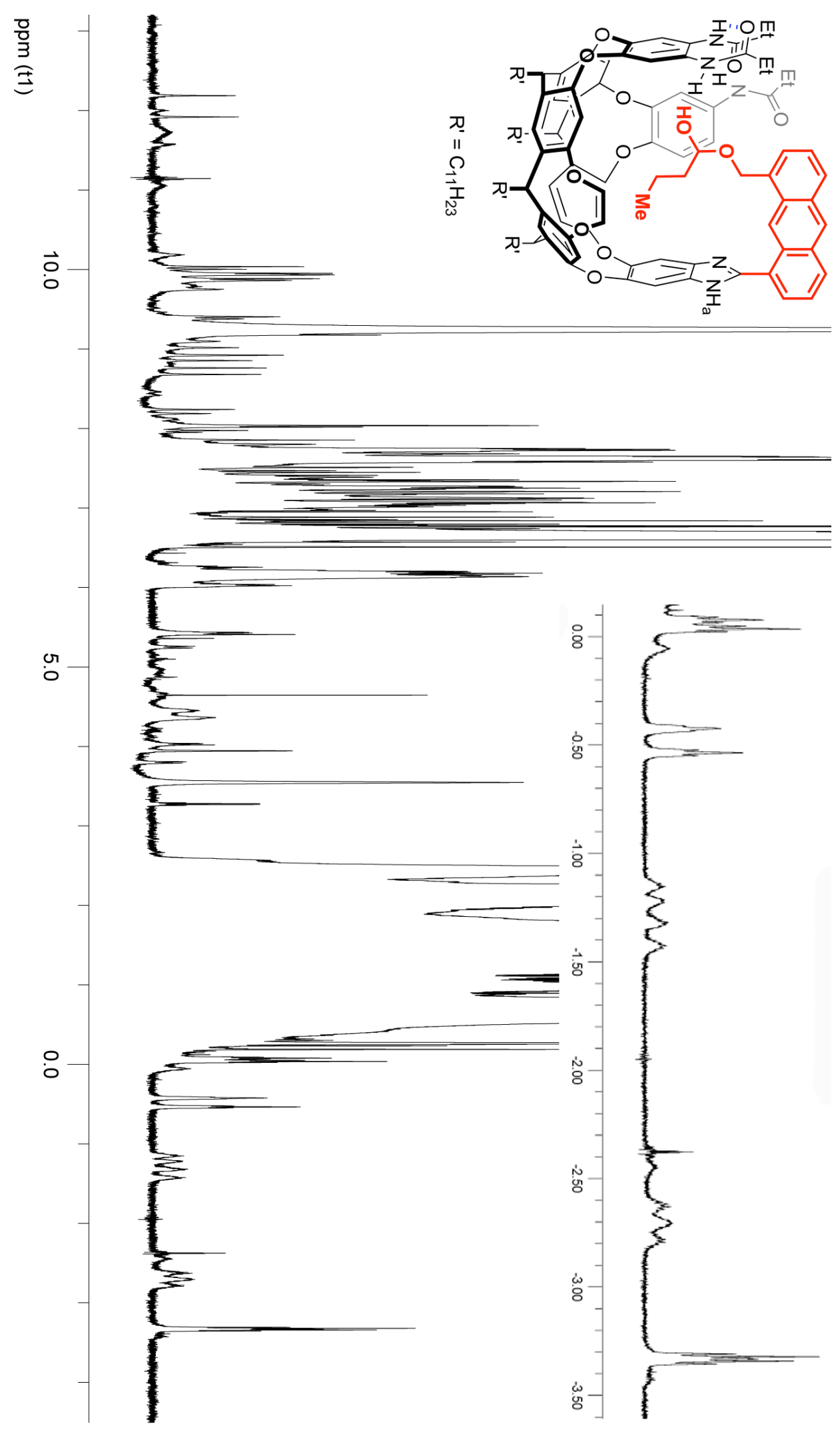


Figure S6. ${ }^{1} \mathrm{H}$ NMR spectrum of the complex $\mathbf{2 \cdot 5}$ formed by exposure of cavitand $\mathbf{2}$ to butyraldehyde 5, $600 \mathrm{MHz}$, mesitylene- $d_{12}, 300 \mathrm{~K}$.

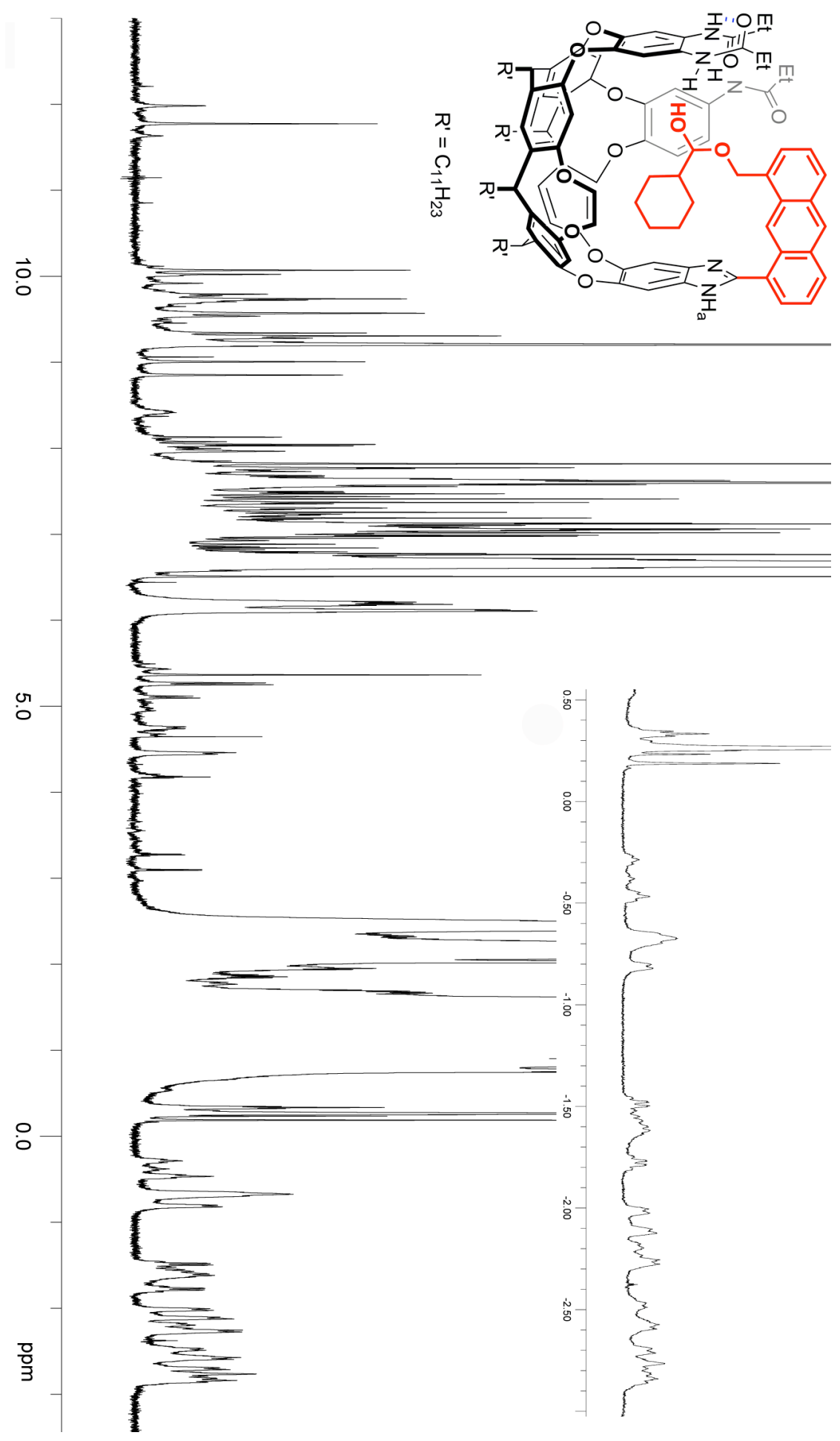

Figure S7. ${ }^{1} \mathrm{H}$ NMR spectrum of the complex $\mathbf{2 \bullet 6}$ formed by exposure of cavitand $\mathbf{2}$ to cyclohexanecarboxaldehyde $\mathbf{6}, 600 \mathrm{MHz}$, mesitylene- $d_{12}, 300 \mathrm{~K}$. Note that peaks for both 
hemiacetal and non-covalently bound guest are seen. The complexity of the spectrum precludes detailed assignment.

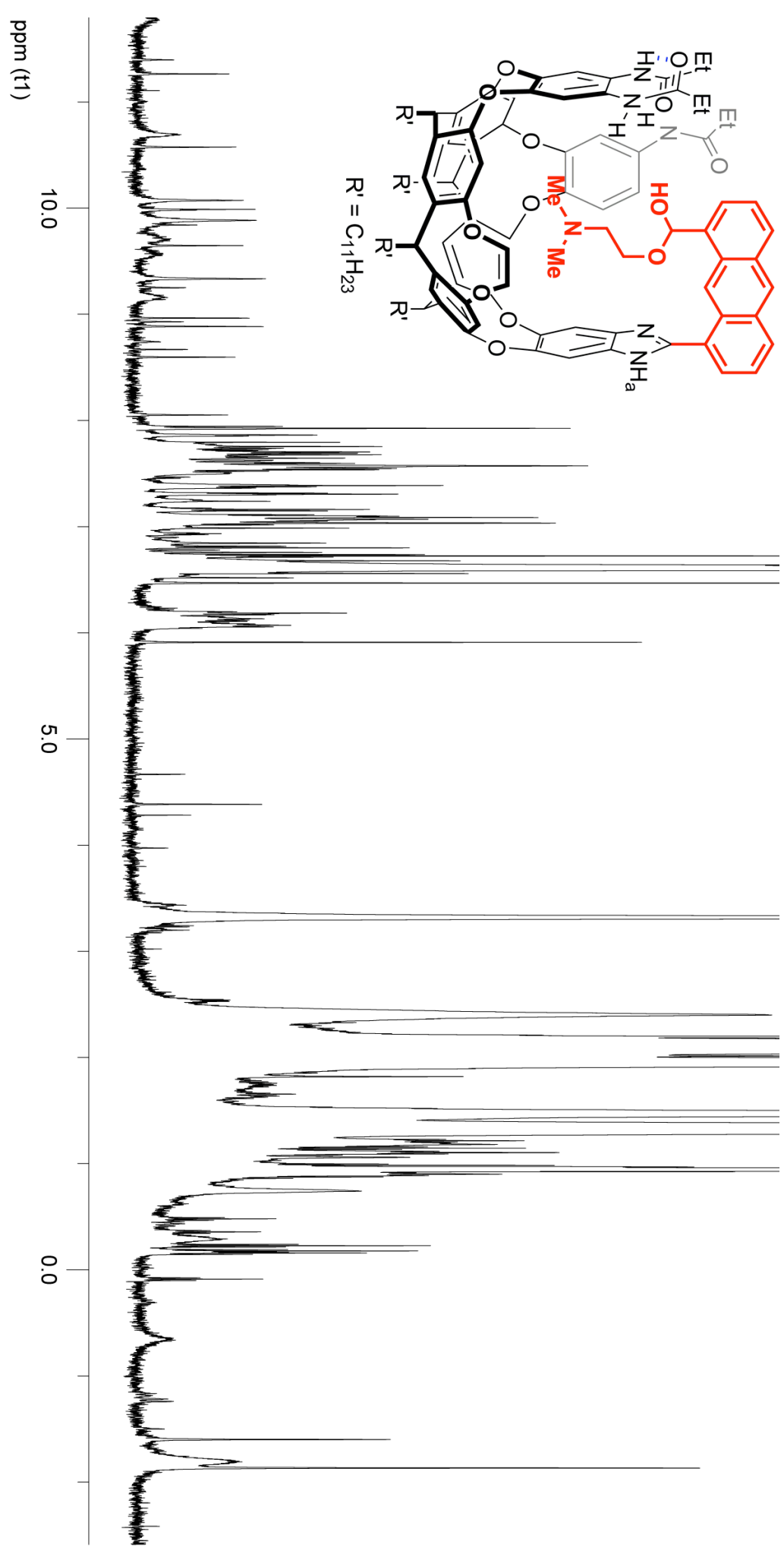


Figure S8. ${ }^{1} \mathrm{H}$ NMR spectrum of the complex $\mathbf{1 \bullet 8}$ formed by exposure of cavitand $\mathbf{1}$ to $N, N$-dimethylethanolamine $8,600 \mathrm{MHz}$, mesitylene- $d_{12}, 300 \mathrm{~K}$.
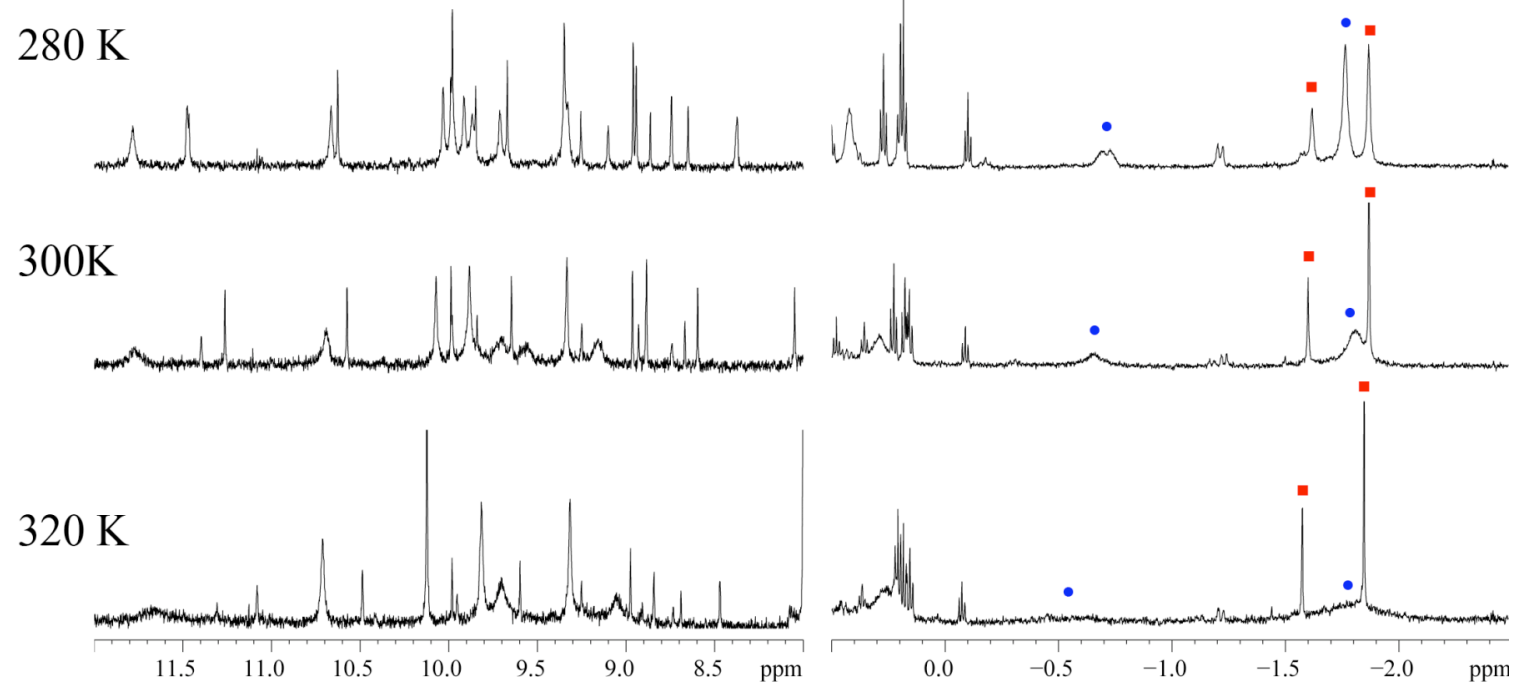

$300 \mathrm{~K}$

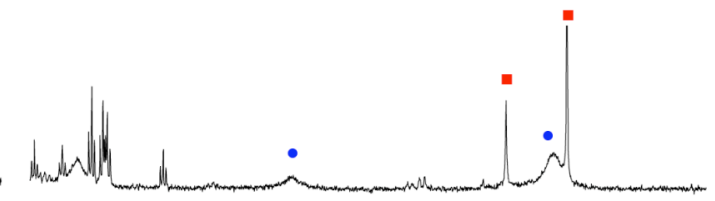

Figure S9. Sections of the ${ }^{1} \mathrm{H}$ NMR spectra at various temperatures of the complex $\mathbf{1 \cdot 8}$ formed by exposure of cavitand $\mathbf{1}$ to $N, N$-dimethylethanolamine $\mathbf{8}, 600 \mathrm{MHz}$, mesitylene$d_{12}$. The broad peaks for guest in the non-covalent complex are flattened by increased in/out exchange rate $(\bullet)$; the sharp peaks for hemiacetal remain $(\square)$.
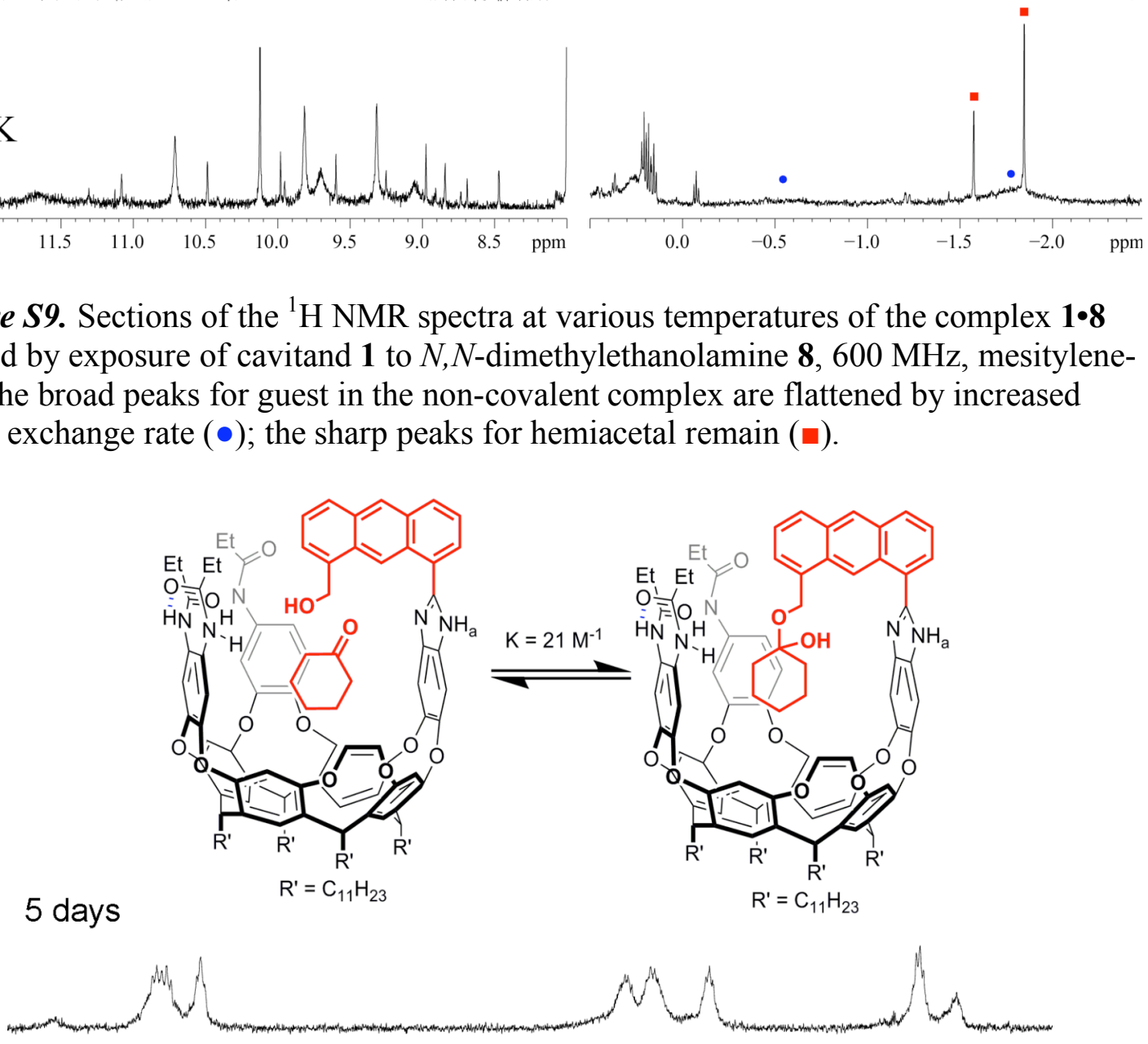

$20 \min$

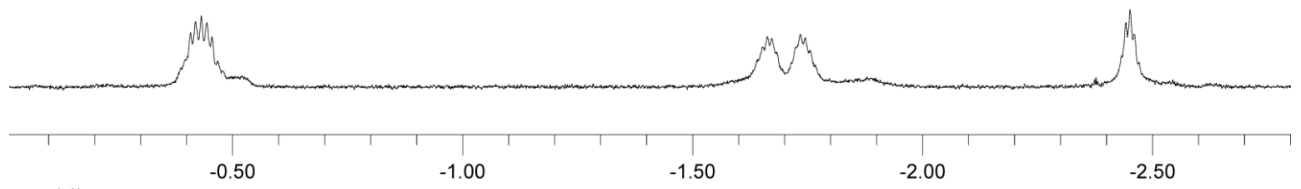

ppm (t1)

Figure S10. Upfield region of the ${ }^{1} \mathrm{H}$ NMR spectra of the complexes formed by exposure of cavitand 2 to cyclohexanone 7 for $20 \mathrm{~min}$ (non-covalent complex) and 5 days 
equilibration (both hemiketal and non-covalent complex), $600 \mathrm{MHz}$, mesitylene- $d_{12}, 300$ $\mathrm{K}$.

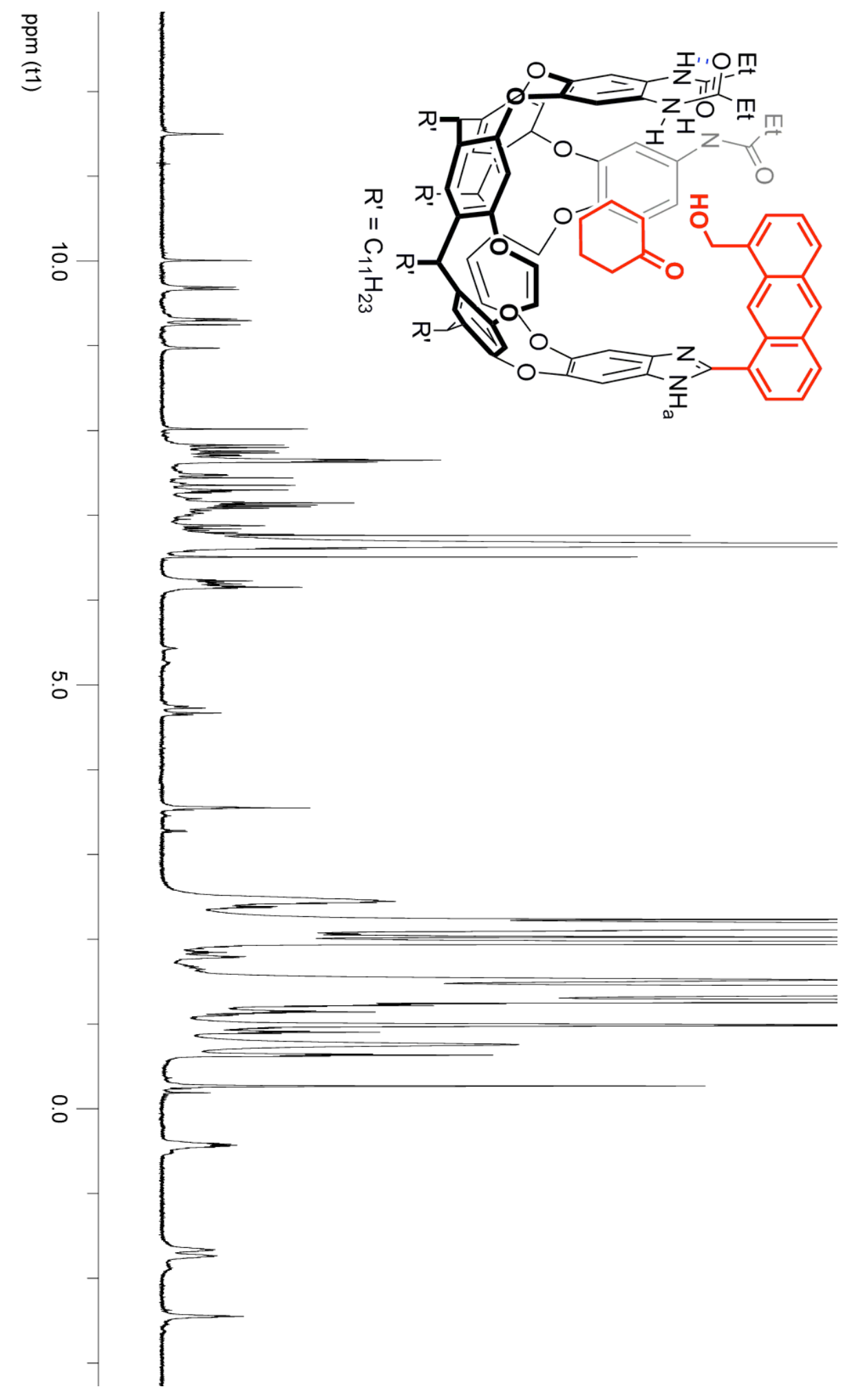


Figure S11. ${ }^{1} \mathrm{H}$ NMR spectrum of the non-covalent complex $\mathbf{2} \cdot \mathbf{7}$ formed by exposure of cavitand 2 to cyclohexanone 7 for $20 \mathrm{~min}, 600 \mathrm{MHz}$, mesitylene- $d_{12}, 300 \mathrm{~K}$.

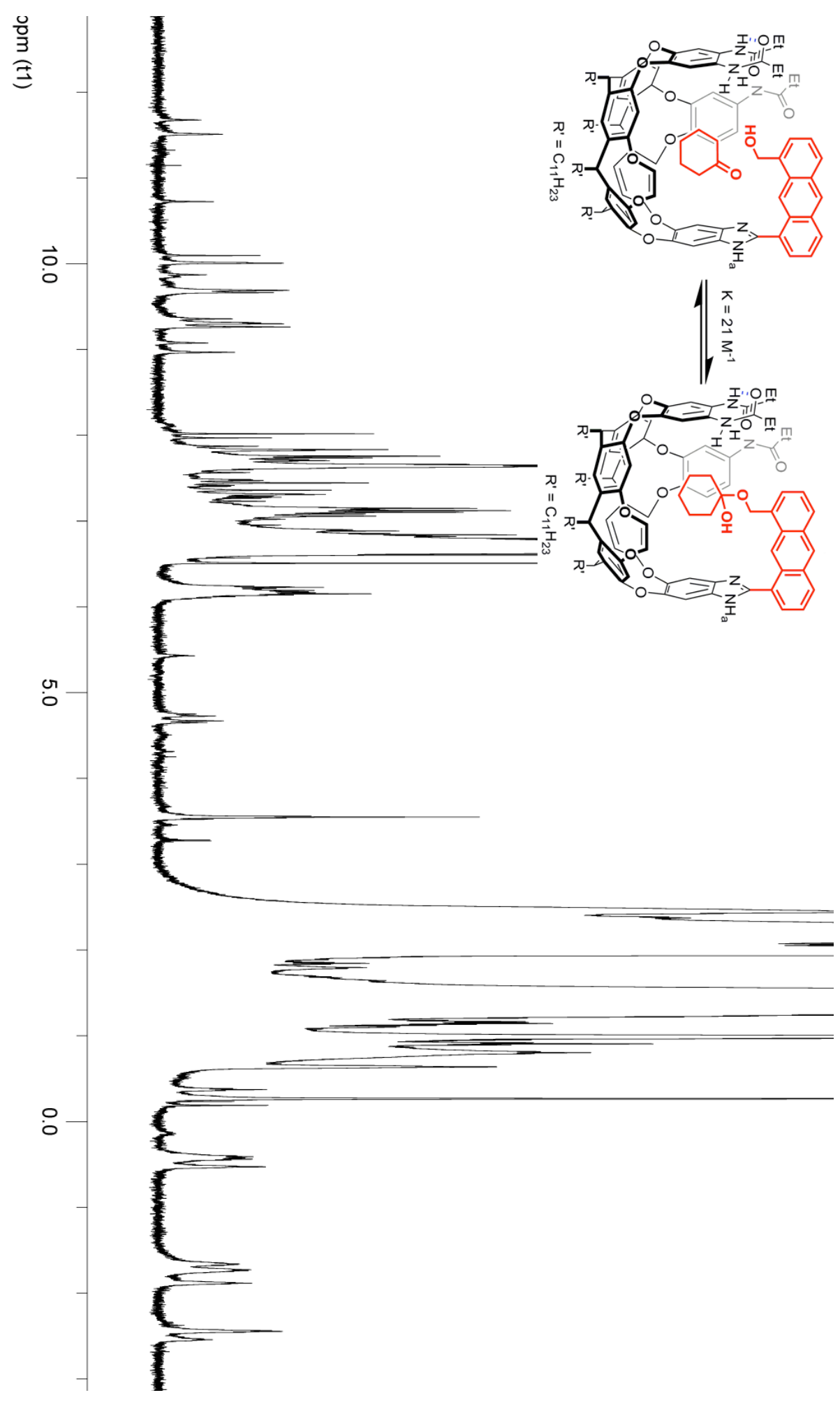


Figure S12. ${ }^{1} \mathrm{H}$ NMR spectrum of the mixture of non-covalent complex and hemiketal $\mathbf{2} \mathbf{7}$ formed by exposure of cavitand $\mathbf{2}$ to cyclohexanone 7 for $5 \mathrm{~d}, 600 \mathrm{MHz}$, mesitylene$d_{12}, 300 \mathrm{~K}$.

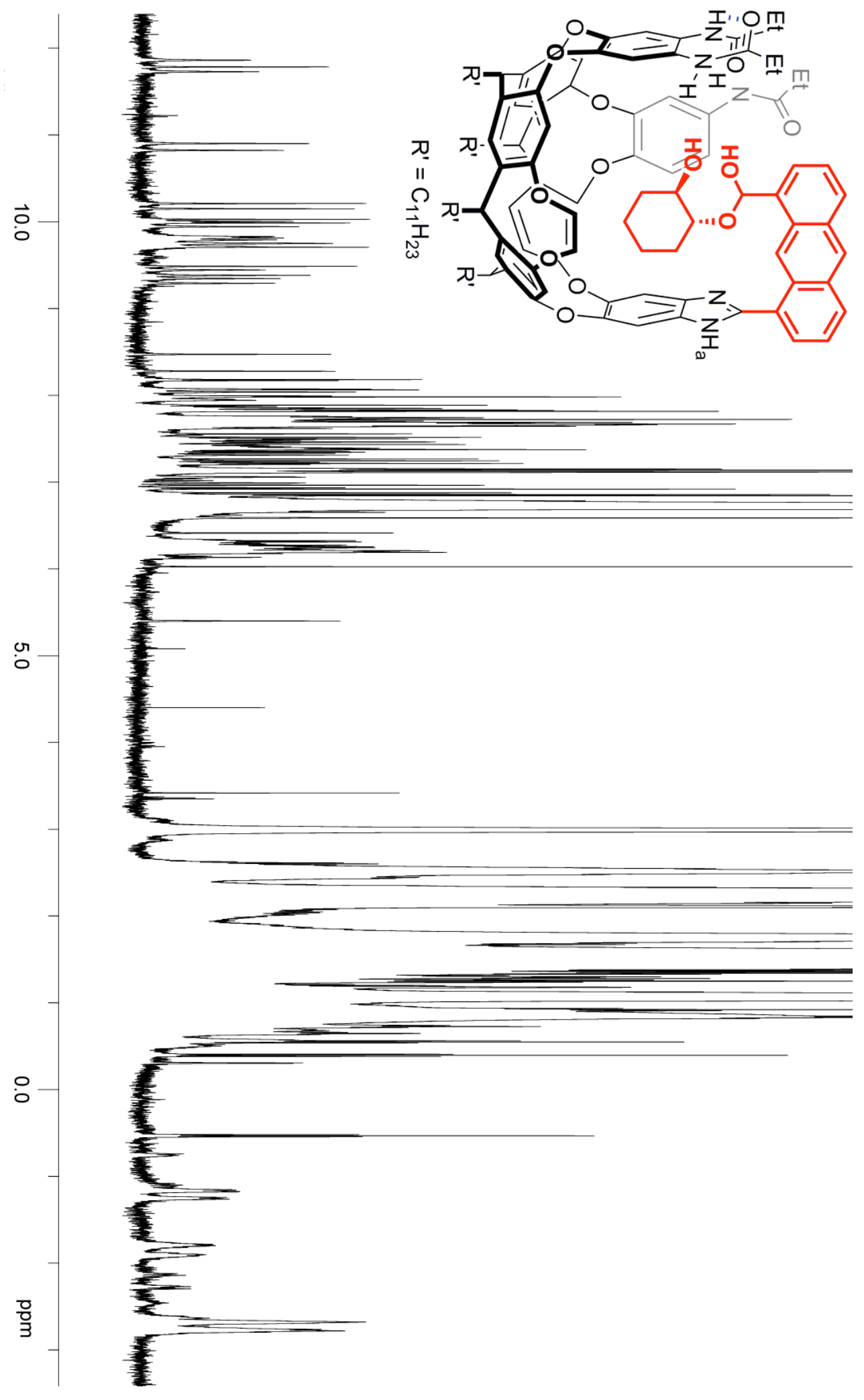


Figure S13. ${ }^{1} \mathrm{H}$ NMR spectrum of the complex $\mathbf{1 \bullet 9}$ formed by exposure of cavitand $\mathbf{1}$ to $(1 R, 2 R)$-trans-cyclohexanediol $9,600 \mathrm{MHz}$, mesitylene- $d_{12}, 300 \mathrm{~K}$.

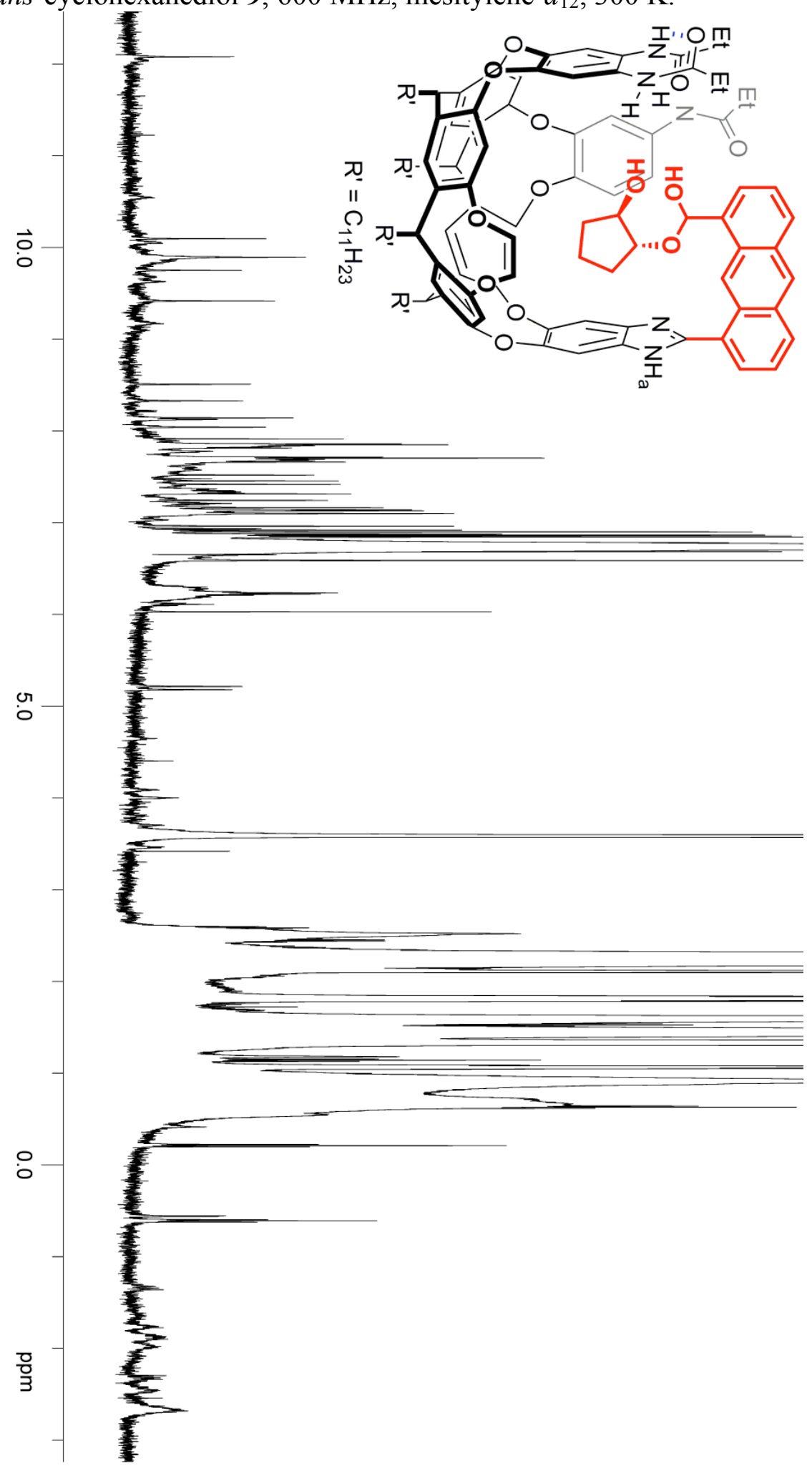


Figure S14. ${ }^{1} \mathrm{H}$ NMR spectrum of the complex $\mathbf{1} \cdot 10$ formed by exposure of cavitand $\mathbf{1}$ to trans-cyclopentanediol 10, $600 \mathrm{MHz}$, mesitylene- $d_{12}, 300 \mathrm{~K}$.

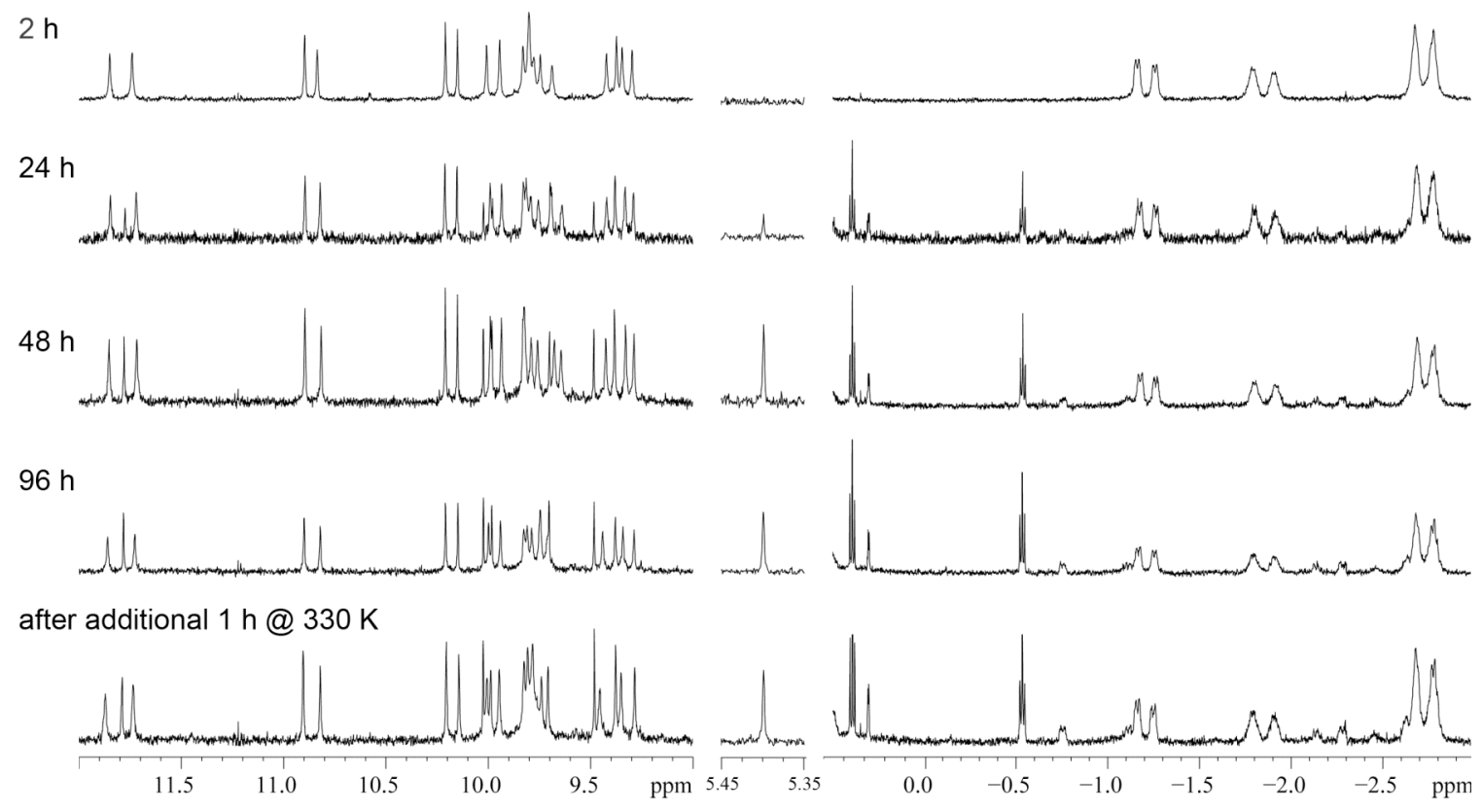

Figure S15. Sections of the ${ }^{1} \mathrm{H}$ NMR spectra of the complex $\mathbf{1 \bullet 9}$ formed by exposure of cavitand 1 to $(1 R, 2 R)$-trans-cyclohexanediol 9 over time, $600 \mathrm{MHz}$, mesitylene- $d_{12}, 300$ $\mathrm{K}$. The buildup of new peaks corresponding to hemiacetal can be seen, most notably the characteristic triplets for the amide methyl groups, $\delta=0.4,-0.8 \mathrm{ppm}$ (see text for explanation).

$1 \mathrm{~h}$
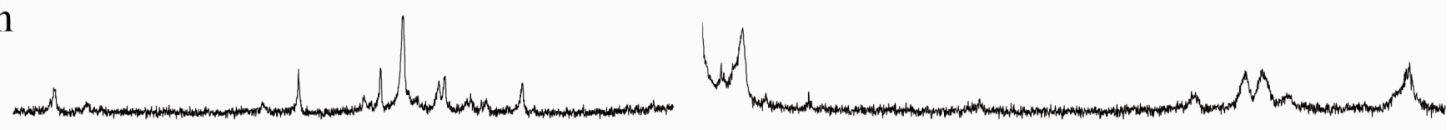

$24 \mathrm{~h}$
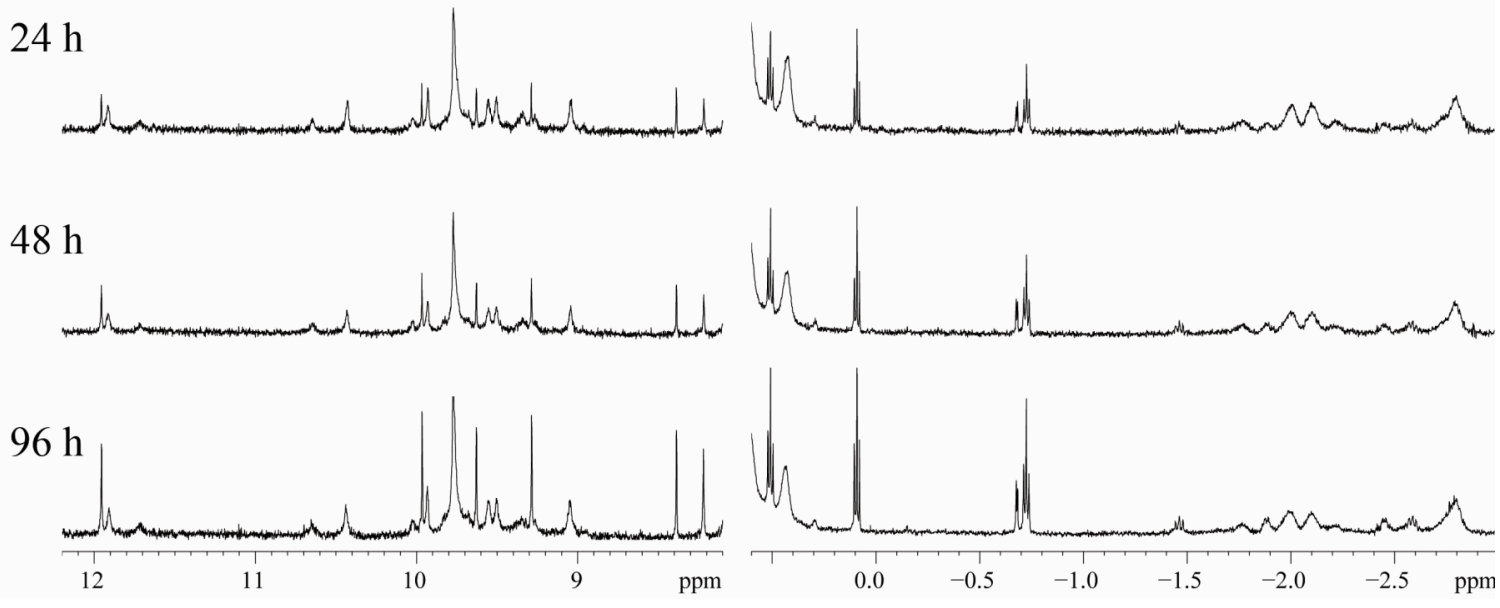

Figure S16. Sections of the ${ }^{1} \mathrm{H}$ NMR spectra of the complex $\mathbf{1} \cdot \mathbf{1 0}$ formed by exposure of cavitand 1 to trans-cyclopentanediol $10,600 \mathrm{MHz}$, mesitylene- $d_{12}, 300 \mathrm{~K}$. The buildup of new peaks corresponding to hemiacetal can be seen, most notably sharp amide NH peaks 
$(\delta=12-8 \mathrm{ppm})$ and the characteristic triplets for the amide methyl groups, $\delta=0.1,-0.7$ ppm (see text for explanation). The diol is a poor non-covalent guest for $\mathbf{1}$, and so the initial complex is unfolded and the H NMR complex. 